\title{
Mindful-S.T.O.P.: Mindfulness Made Easy for Stress Reduction in Medical Students
}

\author{
Phang Cheng Kar ${ }^{1}$, Keng Shian-Ling ${ }^{2}$, Chiang Khai Chong ${ }^{3}$ \\ ${ }^{1}$ Universiti Putra Malaysia, ${ }^{2}$ Duke University, USA, ${ }^{3}$ Turning Point Integrated Wellness Sdn. Bhd., Malaysia.
}

\begin{tabular}{|c|c|c|}
\hline \multirow{2}{*}{\multicolumn{3}{|c|}{$\begin{array}{l}\text { ARTICLE INFO } \\
\text { Received : 09, }\end{array}$}} \\
\hline & & \\
\hline Accepted & : 13/01/2014 & Medical students in Malaysia face enormous amount of stress that can \\
\hline Published & : 01/06/2014 & $\begin{array}{l}\text { compromise their medical training. A brief group Mindfulness-based } \\
\text { Cognitive Therapy (b-MBCT/Mindful-Gym) programme has been }\end{array}$ \\
\hline \multicolumn{2}{|l|}{ KEYWORD } & developed to help medical students cope more effectively with stress. The \\
\hline \multirow{2}{*}{\multicolumn{2}{|c|}{$\begin{array}{l}\text { Medical student } \\
\text { Stress }\end{array}$}} & intervention was found to be effective for reducing stress and increasing \\
\hline & & ive well-being among medical students in University Putra Malaysia \\
\hline \multicolumn{2}{|l|}{$\begin{array}{l}\text { Wellness } \\
\text { Well-being }\end{array}$} & (UPM). One of the training methodologies used in the programme, \\
\hline \multicolumn{2}{|l|}{$\begin{array}{l}\text { Well-being } \\
\text { Mindfulness }\end{array}$} & 'Mindful-S.T.O.P.,' was particularly popular among the students. The aim \\
\hline Mindfulness & & $\begin{array}{l}\text { of this paper is to describe the concept and application of this mindfulness- } \\
\text { based psychological tool (Mindful-S.T.O.P.) for stress reduction in medical }\end{array}$ \\
\hline
\end{tabular}

(c) Medical Education Department, School of Medical Sciences, Universiti Sains Malaysia. All rights reserved.

CORRESPONDING AUTHOR: Dr. Phang Cheng Kar, Department of Psychiatry, Faculty of Medicine \& Health Sciences, UPM (University Putra Malaysia), 43400, Serdang, Selangor Darul Ehsan, Malaysia Tel: 603-2050 1000, Fax: 603-2050 1001, Email address: pckar39011@gmail.com

\section{Introduction}

The number of medical students in Malaysia is growing. As of 2012, there are 34 medical schools in Malaysia, producing about 1700 medical graduates a year $(1,2)$. Effective training of medical students can be seriously compromised if their emotional well-being is not given appropriate attention. Between 29-46\% of medical students in Malaysia experienced significant emotional distress (3-7). Similar worrying trend is reported among medical students worldwide $(8,9)$.

In a recent study of 89 house-officers in Universiti Kebangsaan Malaysia Medical Centre (UKMMC), 42 (47\%) of the trainees reported experiencing moderate to very severe anxiety symptoms (10). Excessive stress in medical students can lead to various psychological disorders $(11,12)$, and negatively affect physical health, interpersonal relationship, and academic performance (12).

\section{'Mindful-Gym' programme for medical students}

In view of the high levels of stress among medical students, a local stress reduction and well-being programme has been developed for medical students in UPM to cope with challenges in medical school. The programme is known as 'Brief Mindfulness-based Cognitive Therapy (b-MBCT),' and was promoted among the students as the 'Mindful-Gym' programme. The b-MBCT/Mindful-Gym is a four-session, twohour per week, group-based training programme, adapted from and based on Mindfulness-based Stress Reduction Programme (MBSR; 13-15), and Mindfulness-based Cognitive Therapy (MBCT; 16-19). 
Mindfulness-based interventions have been specifically shown to be effective in helping medical students reduce stress and increase wellbeing (20-23). The Mindful-Gym programme has been offered to the medical students in UPM since 2010, and also found to be effective for reducing stress and increasing well-being (24, 25). Table 1 shows an outline of the MindfulGym programme.

Table 1: Outline of b-MBCT*/Mindful-Gym programme

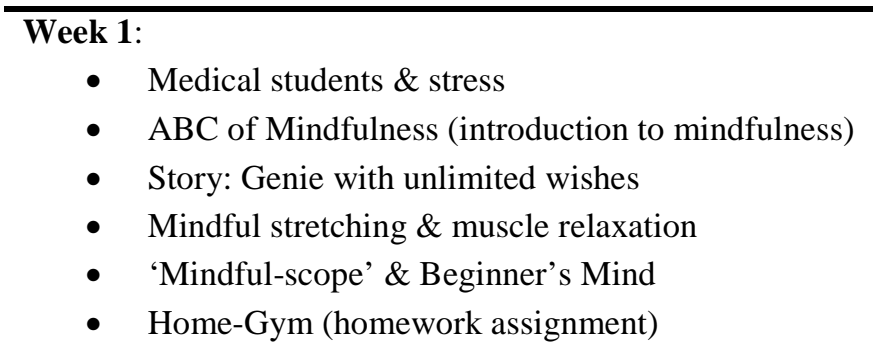

Week 2:

- Review of week 1 lessons, exercises \& discussion of homework

- Song: Happiness is here-and-now (Malaysian version)

- $\quad$ Deep \& Mindful Breathing

- Mindful Imagery - 4 Pleasant States (forest, beach, bathtub, sky)

- Home-Gym (homework assignment)

Week 3:

- $\quad$ Review of week 2 lessons, exercises \& discussion of homework

- 'Mindful-S.T.O.P.' - log in to mindfulness at anytime \& anywhere**

- Mind-Scan I - Identifying Thinking Errors

- Gratitude Workout (Grateful thinking)

- Home-gym (homework assignment)

\section{Week 4:}

- Review of week 3 lessons, exercises \& discussion of homework

- Mind-Scan II - Transforming Thinking Errors

- Body Scan \& Kindness

- Mindfulness Personal Practice Package (MP3) - customising mindfulness practice

- Home-gym (homework assignment)

*b-MBCT- Brief Mindfulness-based Cognitive Therapy

** This is the mindfulness tool or exercise that will be described in this paper

In the programme, participants meet in groups of 15 to 20 members weekly for 2 hours for a total of 4 weeks. Various exercises known as 'mindfulness tools' are introduced for cultivating mindfulness. Participants are informed that as part of the Mindful-Gym programme, they would be taught several psychological tools that they can use to train themselves for mental wellbeing, just as one goes to a gymnasium for physical workout and fitness (hence the programme name, "Mindful-Gym"). One of the tools was noted to be particularly popular among the students, likely due to its simplicity and effectiveness. The tool is called 'MindfulS.T.O.P.'

The objective of this paper is to describe the concept and application of Mindful-S.T.O.P. as a mindfulness-based psychological tool for stress reduction and well-being enhancement in 
medical students. One of the challenges in mindfulness training is integrating mindfulness practice in daily life. Short and frequent practice (e.g. 5 minutes each time for three times per day) may be more helpful than long, but infrequent practice (e.g. 1 hour per month). For that reason, various methods (e.g. 3-minute breathing space practice in MBCT; see below section for further description) have been suggested to help participants to apply short duration of mindfulness practice (mini mindfulness practice) in busy life. Mindful-S.T.O.P. is a technique that builds and expands on the various methods, so that more options are available.

\section{History and concept of mindfulness.}

Before we describe Mindful-S.T.O.P., we will briefly introduce the concept and history of mindfulness, on which Mindful-Gym and Mindful-S.T.O.P. are based. 'Mindfulness' has been a very popular self-help concept lately; fashionable enough to be included in popular book series, such as "The Complete Idiot's Guide to Mindfulness," (26), and "Mindfulness for Dummies" (27). One of the most popular definitions comes from Dr. Jon Kabat-Zinn, the founder of the MBSR programme. He defines mindfulness as "paying attention in a particular way, on purpose, in the present moment, and non-judgmentally" (15). Mindfulness can also be described as a cognitive style that facilitates heightened sense of awareness of 'mindscape' (thought processes, emotions, bodily sensations, etc). Such awareness allows a person to cultivate the ability to respond effectively to challenges, instead of reacting impulsively (28). The concept of mindfulness originated from various ancient spiritual traditions, particularly Buddhism, whereby it is part of the Noble Eightfold Path teaching for happiness. However, mindfulness in contemporary world has been adapted secularly, free from its spiritual roots, as an approach for increasing awareness and responding skilfully to mental processes that contribute to emotional distress and maladaptive behaviour (29).

Mindfulness was first applied in healthcare by Dr. John Kabat-Zinn in 1970's as an 8-week Mindfulness-based Stress Reduction (MBSR) programme for managing chronic pain at the University of Massachusetts Medical Centre, USA (15). Currently, mindfulness-based interventions, e.g. MBSR, MBCT, Acceptance and Commitment Therapy (ACT), and Dialectical Behavioural Therapy (DBT) have been empirically shown to improve physical health (30) reduce stress, anxiety, depression, and suicidality; and improve life satisfaction, empathy, forgiveness, and self-compassion in various populations $(31,32)$.

In Malaysia, mindfulness training in the form of meditation has been popular in the Buddhist community since many years. However, as a mental health programme for stress reduction and well-being, it was only piloted in 2010 by Kuala Lumpur Buddhist Mental Health Association (BMHA) for caregivers and volunteers at Kasih Hospice Foundation. Later in the same year, a similar but more structured programme (b-MBCT/Mindful-Gym) was conducted at UPM for medical students to cope with stress. The programme is ongoing in UPM, and is the one outlined in Table 1. Since 2008, the Malaysian Institute of Islamic Studies (IKIM) has also been organising talks and workshops on mindfulness from an Islamic perspective (33). Having provided the background information on mindfulness, we shall now describe the concept and application of Mindful-S.T.O.P. (basic and expanded).

\section{Concept and application of Mindful-S.T.O.P.}

\section{Basic Mindful-S.T.O.P.}

Mindful-S.T.O.P. is an acronym for a four-step approach that can be used to 'log in' and conveniently cultivate mindfulness at anytime and anywhere. This psychological tool/strategy is taught during week 3 (the third session) of the programme. The Mindful-Gym instructor usually invites participants ('Mindful-Gymers') to begin the Mindful-S.T.O.P. practice by ringing a mindfulness bell (an electronic bell is available from http://www.mindfulnessdc.org/mindfulclock.html), and says, "Let's welcome ourselves home, and log in to the present moment by taking a MindfulS.T.O.P." An alternative opening instruction is, "Let's 'Touch ' $\mathrm{n}$ Go'...touch the present 
moment ('NOW'), and go to 'HERE,' by taking a Mindful-S.T.O.P.” Note: "Touch n Go" is the name of a popular smart card used by Malaysian toll expressway and highway operators as the sole electronic payment system. The catchy phrase, 'Let's Touch ' $n$ Go' is used as it can easily remind the participants of the concept of 'HERE-and-NOW.' Awareness of the present moment is a state of mind that is encouraged in mindfulness training. In cultivating this state, participants are reminded to give full, wise and kind attention to whatever that they are experiencing at the present moment (also known as 'HERE-and-NOW'), instead of constantly ruminating - regretting over past mistakes, and worrying about future problems.

The opening invitation to mindfulness practice is followed by step-by-step instructions to practice Mindful-S.T.O.P. Table 2 summarises the guided instructions and rationale for each step of the basic Mindful-S.T.O.P. practice.

Table 2: Instructions and rationale of the four-step basic Mindful-S.T.O.P. practice

\begin{tabular}{|c|c|c|}
\hline Acronym & Guided instruction & Rationale \\
\hline $\begin{array}{l}\text { Step 1: } \\
\text { S } \\
\text { (Stop) }\end{array}$ & 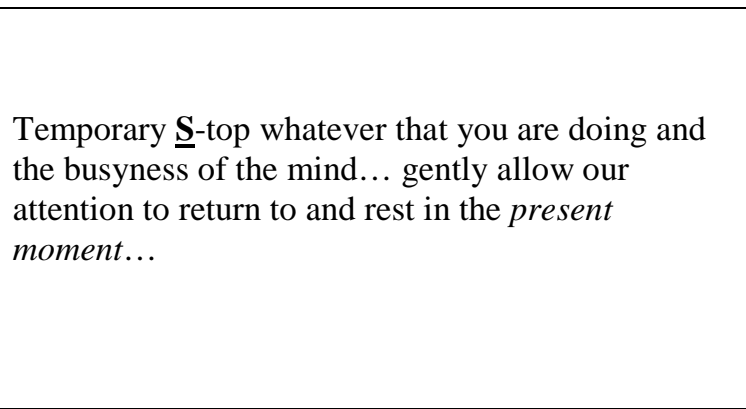 & $\begin{array}{l}\text { Repeating pausing (S), followed by } \\
\text { the other steps (T.O.P.) is helpful to } \\
\text { condition the mind to stay more and } \\
\text { more in the present moment. } \\
\text { This is how one can train the mind } \\
\text { to unlock itself from a compulsive } \\
\text { doing mode (also known as } \\
\text { 'mindlessness' or 'autopilot mode' } \\
\text { in mindfulness training). }\end{array}$ \\
\hline $\begin{array}{l}\text { Step 2: } \\
\text { T } \\
\text { (Take deep \& } \\
\text { mindful breaths) }\end{array}$ & $\begin{array}{l}\text { T-ake } 3 \text { slow deep breaths } \\
\text { (Deep Relaxation Breathing)... } \\
\text {...allow your attention to rest on the movement of } \\
\text { your breath... breathing in, I know I am breathing } \\
\text { in, breathing out, I know that I am breathing out } \\
\text { (Mindful Breathing)... } \\
\text { Note: one has the choice of either doing 'Deep } \\
\text { Relaxation Breathing' or 'Mindful Breathing' or both, } \\
\text { depending on personal preference. }\end{array}$ & $\begin{array}{l}\text { 'Deep Relaxation } \\
\text { helps induce instant relaxation' } \\
\text { effects. Taking little breaks to relax } \\
\text { throughout the day may make } \\
\text { challenges more manageable. It also } \\
\text { helps to support memory and } \\
\text { effective learning (34) } \\
\text { 'Mindful Breathing' is useful for } \\
\text { anchoring our attention on the } \\
\text { present moment, instead of getting } \\
\text { lost in unhelpful thoughts (e.g. } \\
\text { worries and regrets). }\end{array}$ \\
\hline $\begin{array}{l}\text { Step 3: } \\
\text { O } \\
\text { (Observe } \\
\text { the present } \\
\text { moment) }\end{array}$ & $\begin{array}{l}\text { As you are breathing in and out, } \\
\text { o-bserve the present moment: } \\
\text { a) SOUND (e.g. fan, birds chirping, and people } \\
\text { talking), and/or } \\
\text { b) SIGHT (e.g. tree, clouds, flowers), and/or } \\
\text { c) SENSATION (e.g. on the face, between the } \\
\text { buttock and seat, hands and steering while } \\
\text { driving)... }\end{array}$ & $\begin{array}{l}\text { This enables us to temporarily } \\
\text { disengage from our busy thoughts, } \\
\text { and shift our attention to a 'free- } \\
\text { gear' mode, resting and relaxing in } \\
\text { the present moment. }\end{array}$ \\
\hline $\begin{array}{l}\text { Step 4: } \\
\text { P } \\
\text { (Proceed with a } \\
\text { smile) }\end{array}$ & $\begin{array}{l}\text { P-roceed with whatever you need to do } \\
\text { with a SMILE... }\end{array}$ & $\begin{array}{l}\text { Smiling has been reported to relax } \\
\text { the mind-body, facilitates helpful } \\
\text { thoughts, and improves } \\
\text { interpersonal relationships. When } \\
\text { the mind is calm and in 'smiley' } \\
\text { mode, problem solving is likely to } \\
\text { be more effective (35- } 37 \text { ). }\end{array}$ \\
\hline
\end{tabular}


The entire Mindful-S.T.O.P. practice can be completed within one minute. For a start, students are recommended to practice MindfulS.T.O.P. at least three times per day. Any obstacles to practice will be discussed, and followed by suggestions to customise MindfulS.T.O.P for individual student's needs. When they are familiar with the practice, the duration and frequency of practice can be expanded (e.g. three minutes each time, five times per day).

One of the strengths of Mindful S. T. O. P. is that it can be practised within a short duration, and on a regular basis. Mindfulness exercises that take up more time (e.g. 45 minutes per day as in the original MBSR program) is likely to be perceived as a burden by the medical students. The trainers of mindfulness-based programme (known as 'Koru') for students in Duke University also reported similar experience. Short and regular practice (i.e. four 75-minute classes, and 10 minutes of daily practice) are helpful to engage the students in mindfulness training $(38,39)$. As a convenient and culturally acceptable way of practicing, the Muslim students in the programme are encouraged to practice Mindful-S.T.O.P. before or after their daily prayer (i.e. five times per day). Interestingly, with mindfulness training, several participants reported better concentration and a greater sense of connection to Allah/God/Buddha during prayer. Students may also choose to practice Mindful-S.TO.P. before or after turning off their computers.

The use of acronym (S.T.O.P.) for mindfulness training in Mindful-Gym is useful as it is something familiar to medical students; they often use similar approach as mnemonics for remembering medical facts. The use of mnemonics is common in DBT, which is developed for people with borderline personality disorder (40). Similar, but simpler 'S.T.O.P.' approach: 1) S - Stop, 2) T - Take a breath, 3) $\mathrm{O}$ - Observe thoughts, emotions or sensations, and 4) P - Proceed and respond more effectively, has also been recommended for informal mindfulness practice (41).
This Mindful-S.T.O.P. approach is also similar to the '3-Minute Breathing Space' (AwarenessGathering-Expansion) used in MBCT (42). The practice involves three steps: 1 . Awareness adopting an erect and dignified body posture, and registering the experience right now; thoughts, feelings and bodily sensations, 2. Gathering - gently redirect full attention to breathing, and 3. Expanding - expanding the field of awareness around breathing, so that it includes a sense of the body as whole, including body posture and facial expression. Another similar practice is the 5-minute mindfulness of breathing 'full stops' or even shorter, i.e. 15-30 seconds of mindfulness of breathing 'commas' (20).

Compared to these approaches, Mindful S. T. O. P. has added advantage of being easier to remember since it is in the form of an acronym. Furthermore, this acronym (S.T.O.P.) has added meanings (stop resisting reality) which are related to the principles of mindfulness acceptance, contentment, friendliness, kindness, equanimity (43). Having mindfulness tools that are easy to remember and practice is very important, as medical students' mind are often overloaded with tons of medical facts. Interestingly, this emphasis is in accordance with the meaning of the word for mindfulness in Pali (ancient language of Buddhist scriptures) 'Sati'(44). Sati literally means 'to remember,' and includes both memory of the past, and prospective memory of the present and future $(45,44)$.

\section{Expanded Mindful-S.T.O.P.}

Mindful S. T. O. P. can also be expanded into a lengthier practice, depending on an individual's preference and need in a given situation, and integrated with other mindfulness-based exercises/tools taught in the programme. For example, we can easily expand 'Step 2' (Take deep and mindful breathing) into 3-minute, 5-minute, 10-minute, 20-minute or longer mindfulness of breathing practice. In this way, our attention to the present moment can be gradually trained and improved in 'MindfulGym' (just as body builders strengthen their muscles in a physical gymnasium). In a 
randomised controlled trial, mindfulness meditation (4-week, 20 minutes per day, twice a day) was found to significantly improve sustained attention, as compared to relaxation training and no training (control group) (46). This is a useful fact to encourage participants in Mindful-Gym to gradually strengthen their

Table 3: Expanded Mindful-S.T.O.P. practice mindfulness practice. Table 3 summarises some of the ways that Mindful-S.T.O.P. practice can be expanded for further mindfulness-based trainings in Mindful-Gym.

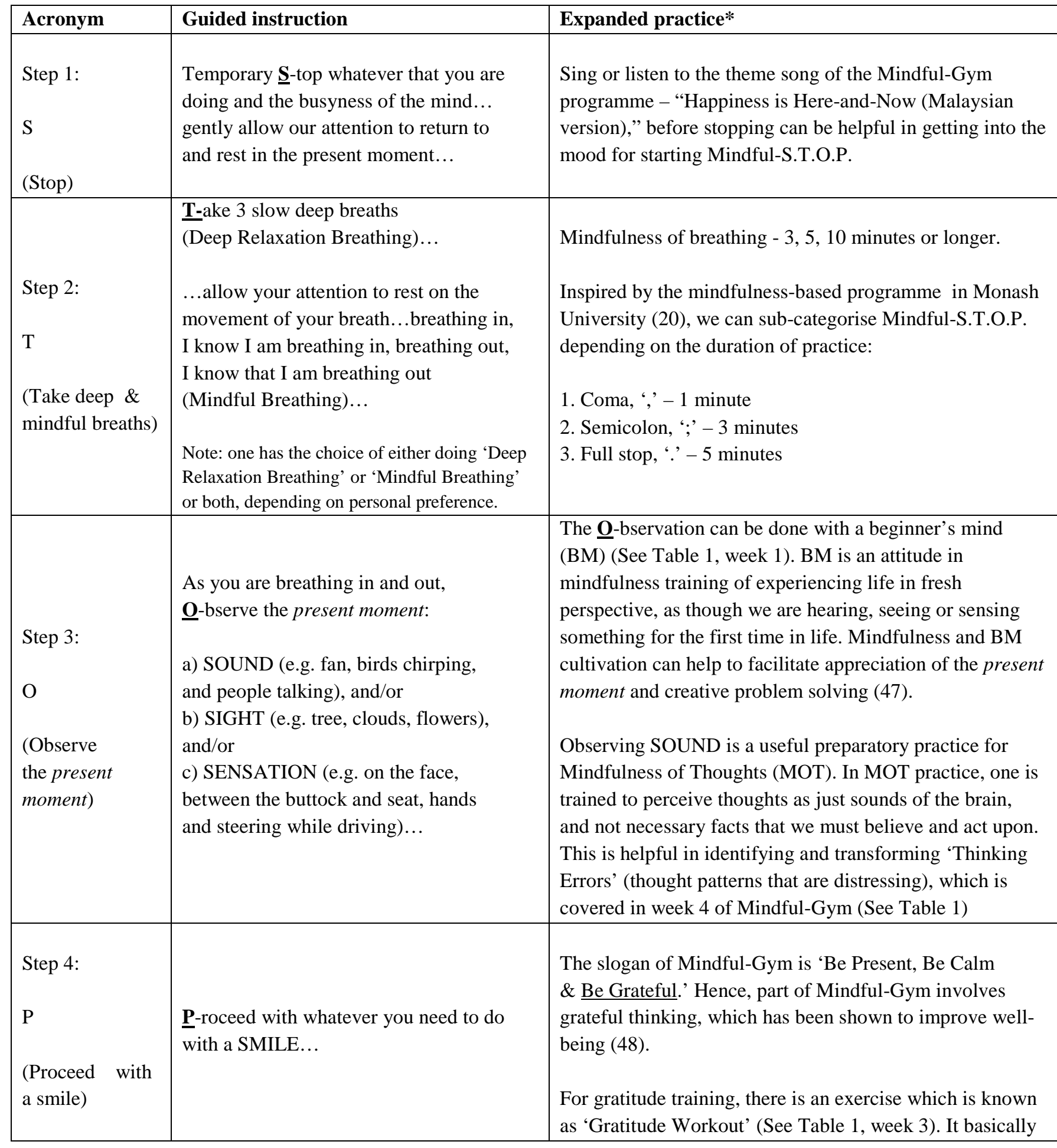




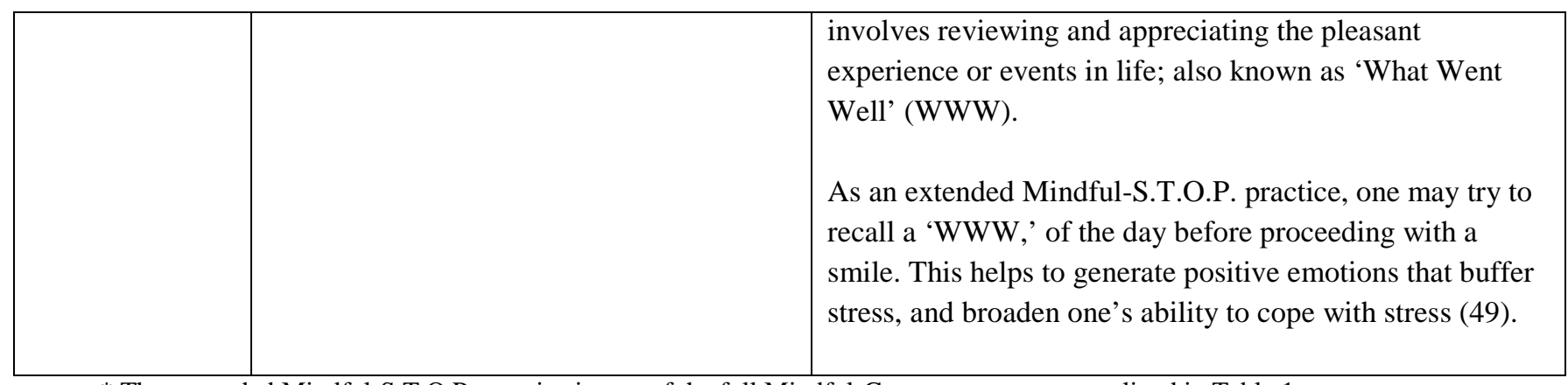

* The expanded Mindful-S.T.O.P. practice is part of the full Mindful-Gym programme as outlined in Table 1

\section{Benefits of Mindful-S.T.O.P.}

Below are a few testimonials on the benefits of Mindful-S.T.O.P.:

"As a medical student, handling stress, and juggling time for family, friends as well as studies are often harder than you can imagine. Mindful-S.T.O.P. is a simple way to remind myself of the importance of being NOW and being YOU. In less than 5 minutes, irrespective of where you are, you can refresh yourself, and face daily challenges with a smile."

"Mindful-S.T.O.P. reminds me to go back to the here-and-now. I feel more relax after doing it. After regular practice and benefits, it seems like is has become part of my habit."

"Mindful-S.T.O.P is a very important part of my daily life. Whenever I feel distracted or discouraged by the many "To Do's" in my log book, I'll take a Mindful S.T.O.P. Just a few minutes, it can change the way I feel, and look at things - more relax and positive. Without it, clinical years would be overwhelming."

"Mindful-S.T.O.P. helps me to focus in everything I do, and stop thinking of problems and unnecessary things, especially while studying. When I practice it with ' $W W W$ ' (grateful thinking), it makes me feel happy. It spreads to the people around me too - happiness is contagious."

\section{Future Training and Research Recommendations for Mindful-S.T.O.P.}

In view of the potential benefits of using Mindful-S.T.O.P. (basic and extended) in mindfulness training among medical students, the following training and research recommendations are suggested:

1. Studies to support the preference and effectiveness of Mindful-S.T.O.P, practice for cultivating mindfulness among medical students.

2. Exploring the use of Mindful-S.T.O.P. practice among busy health care providers in hospitals (e.g. house officers, doctors, nurses, and paramedics).

3. Exploring the use of Mindful-S.T.O.P. practice among patients in busy clinics, and students in school setting.

4. Qualitative studies on experience in using Mindful-S.T.O.P. as a tool for self-care among helping professionals (e.g. mental health professionals, doctors, nurses).

5. Developing computer and phone applications that utilise the principles of Mindful-S.T.O.P.

\section{Conclusion}

Based on the authors' experience in implementing b-MBCT/ Mindful-Gym programme in UPM, Mindful-S.T.O.P. seems to be an effective approach for medical students to cultivate mindfulness for stress reduction and well-being. Its simplicity and flexibility make it an essential pedagogy in mindfulness training. Therefore, it should be further explored and 
expanded for potential application in mindfulness education.

\section{Reference}

1. Lum M. Good Doctoring. The Star Online. 2012 July 29; Available from: http://thestar.com.my/columnists/story.asp?fi $\mathrm{le}=/ 2012 / 7 / 29 /$ columnists/thedoctorsays $/ 117$ $16017 \&$ sec $=$ thedoctorsays.

2. Sivanandam H. 1,659 medical students graduated last year. The Sun Daily. 2011 December 23. Available from: http://www.thesundaily.my/news/247230.

3. Johari A, Hassim I. Stress and Coping strategies among medical students in National University of Malaysia, Malaysia University of Sabah, and Universiti Kuala Lumpur Royal College of Medicine Perak. Journal of Community Health. 2009;15:106115.

4. Sherina MS, Rampal L, Kaneson N. Prevalence of emotional disorders among medical students in a Malaysian university. Asian Pacific Family Medicine. 2003;2:213217.

5. Sherina MS, Rampal L, Kaneson N. Psychological stress among undergraduate medical students. Medical Journal of Malaysia. 2004;59(2):207-211.

6. Yusoff MSB, Abdul Rahim AF, Yaacob MJ. Prevalence and sources of stress among Universiti Sains Malaysia medical students. Malaysian Journal of Medical Sciences. 2010;17(1):30-37.

7. Zaid ZA, Chan SC, Ho JJ. Emotional disorders among medical students in a Malaysian private medical school. Singapore Medical Journal. 2007;48(10):895-899.

8. Dyrbye LN, Thomas MR, Shanafelt TD. Systematic review of depression, anxiety, and other indicators of psychological distress among U.S. and Canadian medical students. Academic Medicine. 2006;81(4):354-373.

9. Shapiro SL, Shapiro DE, Schwartz GER. Stress management in medical education: A review of the literature. Academic Medicine. 2000;75(7):748-759.

10. Tan SMK, Jong SC, Chan LF, Jamaludin NA, Phang CK, Jamaluddin NS. Physician, heal thyself: The paradox of anxiety amongst house officers and work in a teaching hospital. Asia-Pacific Psychiatry. 2013;5:74-81.

11. Rosenthal JM, Okie S. White coat, mood indigo - Depression in medical school. New
England Journal of Medicine. 2005;353(11):1085-1088.

12. Schwenk TL, Davis L, Wimsatt LA. Depression, stigma, and suicidal ideation in medical students. Journal of the American Medical Association. 2010;304(11):11811190.

13. Chiesa A, Serretti A. Mindfulness-based stress reduction for stress management in healthy people: A review and meta-analysis. Journal of Alternative and Complementary Medicine. 2009;15(5):593-600.

14. Grossman P, Niemann L, Schmidt S, Walach $\mathrm{H}$. Mindfulness-based stress reduction and health benefits: A meta-analysis. Journal of Psychosomatic Research. 2004;57(1):35-43.

15. Kabat-Zinn J. Mindfulness-based interventions in context: Past, present, and future. Clinical Psychology: Science and Practice. 2003;10(2):144-156.

16. Bondolfi G, Jermann F, der Linden MV, Gex-Fabry M, Bizzini L, Rouget BW. Depression relapse prophylaxis with Mindfulness-Based Cognitive Therapy: Replication and extension in the Swiss health care system. Journal of Affective Disorders. 2012;122(3):224-231.

17. Ree MJ, Craigie MA. Outcomes following mindfulness-based cognitive therapy in a heterogeneous sample of adult outpatients. Behaviour Change. 2007;24(2):70-86.

18. Teasdale JD, Segal ZV, Williams JMG, Ridgeway VA, Soulsby JM, Lau MA. Prevention of relapse/recurrence in major depression by Mindfulness-Based Cognitive Therapy. Journal of Consulting and Clinical Psychology. 2000;68(4):615-623.

19. Williams JMG, Russell I, Russell D. Mindfulness-Based Cognitive Therapy: Further Issues in current evidence and fture research. Journal of Consulting and Clinical Psychology. 2008;76(3):524-529.

20. Hassed C, de Lisle, Sullivan G, Pier C. Enhancing the health of medical students: outcomes of an integrated mindfulness and lifestyle program. Advances in health sciences education: theory and practice. 2009;14(3):387-398.

21. Rosenzweig S, Reibel DK, Greeson JM, Brainard GC, Hojat M. Mindfulness-based stress reduction lowers psychological distress in medical students. Teaching and Learning in Medicine. 2003;15(2):88-92.

22. Shapiro SL, Schwartz GE, Bonner G. Effects of mindfulness-based stress reduction on medical and premedical students. Journal of Behavioural Medicine. 1998;21(6):581-599. 
23. Warnecke E, Quinn S, Ogden K, Towle N, Nelson MR. A randomised controlled trial of the effects of mindfulness practice on medical student stress levels. Medical Education. 2010;45(4):381-388

24. Phang CK, Chiang KC, Ng LO, Oei TPS. Effectiveness of brief Mindfulness-based Cognitive Therapy for stress reduction among medical students in a Malaysian university: a pilot study. Paper presented at the International Mindfulness Conference, Rome; 2013.

25. Phang CK, Firdaus M, Sherina MS, Normala I, Noor Jan, Hamidin A. Effectiveness of brief mindfulness-based training for stress reduction and well-being among medical students in a Malaysian university: results from a controlled trial. Paper presented at the Faculty Research Week Poster Competition, Faculty of Medicine \& Health Sciences, UPM; 2013.

26. Ihnen A, Carolyn, F. The Complete Idiot's Guide to Mindfulness: New York: Alpha; 2008.

27. Alidina S, Steven DH. Mindfulness for Dummies. West Sussex : John Wiley \& Sons; 2010.

28. Kostanski M, Hassed C. Mindfulness as a concept and a process. Australian Psychologist. 2008;43(1):15-21.

29. Bishop SR, Lau M, Shapiro S, Carlson L, Anderson ND, Carmody J. Mindfulness: A proposed operational definition. Clinical Psychology: Science and Practice. 2004;11(3):230-241.

30. Mars TS, Abbey H. Mindfulness meditation practise as a healthcare intervention: A systematic review. International Journal of Osteopathic Medicine. 2012;13(2):56-66.

31. Chiesa A, Serretti A. Mindfulness based cognitive therapy for psychiatric disorders: A systematic review and meta-analysis. Psychiatry Research. 2011;187(3):441-453.

32. Keng SL, Smoski MJ, Robins CJ. Effects of mindfulness on psychological health: A review of empirical studies. Clinical Psychology Review. 2011; 1(6):1041-1056.

33. IKIM. Workshop on "Stress Management". IKIM's programme 2013. Available from: http://www.ikim.gov.my/file/program_ikim_ 2013.pdf.

34. Dewar M, Alber J, Butler C, Cowan N, Della Sala S. Brief wakeful resting boosts new memories over the long term. Psychol Sci. 2012; 23(9): 955-960.

35. Johnson KJ, Waugh CE, Fredrickson BL. Smile to see the forest: Facially expressed positive emotions broaden cognition. Cognition \& Emotion. 2010;24(2):299-321.

36. Kraft TL, Pressman SD. Grin and bear it: the influence of manipulated facial expression on the stress response. Psychol Sci. 2012; 3(11): 1372-1378.

37. Strack F, Martin LL, Stepper S. Inhibiting and facilitating conditions of the human smile: a nonobtrusive test of the facial feedback hypothesis. J Pers Soc Psychol. 1988;54(5):768-777

38. Rogers HB. Koru: Teaching mindfulness to emerging adults. New Directions for Teaching and Learning. 2013;134:73-81.

39. Rogers HMM. Mindfulness for the next generation: helping emerging adults manage stress and lead healthier lives. New York: Oxford University Press; 2012.

40. Linehan M. Skills training manual for treating Borderline Personality Disorder. New York: Guilford Press; 2003.

41. Stahl B, Goldstein E. A mindfulness-based stress reduction workbook. Oakland, CA: New Harbinger Publications; 2010.

42. Segal ZV, Williams JMG, Teasdale JD. Mindfulness-based cognitive therapy for depression: a new approach to preventing relapse. New York: Guilford Press; 2002.

43. Phang CK, Oei TPS. From mindfulness to meta-mindfulness: Further Integration of meta-mindfulness concept and strategies into Cognitive Behavioural Therapy. Mindfulness. 2012;3(2):104-116.

44. Sujato. A history of mindfulness: How insights worsted tranquillity in the Satipatthana Sutta. Taipei: The Corporate Body of the Buddha Educational Foundation; 2005.

45. Kang C, Whittingham K. Mindfulness: A dialogue between Buddhism and Clinical Psychology. Mindfulness. 2010; 1-13.

46. Semple RJ. Does mindfulness meditation enhance attention? A randomised controlled trial. Mindfulness. 2010;1(2):121-130.

47. Dhlman S. Mindfulness and the art of living creatively: Cultivating a creative life by minding our mind. Journal of Social Change. 2012;4(1):24-33.

48. Wood AM, Froh JJ, Geraghty AWA. Gratitude and well-being: A review and theoretical integration. Clinical Psychology Review. 2010;30(7):890-905.

49. Fredrickson BL. The broaden-and-build theory of positive emotions. Philosophical Transactions of the Royal Society B: Biological Sciences 2004;359(1449):13671377. 